\title{
Literature review of studies on the effectiveness of nurses ability to order and interpret X-rays
}

\author{
Belinda Free, NP, MN, Grad Dip Crit Care, BN, RNa, \\ Geraldine A. Lee, PGDE, BSc, RGN ${ }^{b}$, , Adam Bystrzycki, MBBS FACEM ${ }^{a}$
}

\author{
a The Alfred Emergency and Trauma Centre, Commercial Road, Prahran, Victoria 3004, Australia \\ b School of Nursing \& Midwifery, Latrobe University, Bundoora, Melbourne, Victoria 3086, Australia
}

Received 22 February 2008; received in revised form 14 November 2008; accepted 24 November 2008

\section{KEYWORDS \\ Nurse practitioner; Emergency department; Radiography; Interpretation; Accuracy; Ordering}

\begin{abstract}
Summary
Background: The role of radiography within the context of the emergency department (ED) is to aid the physician in the accurate clinical diagnosis of trauma or illness and traditionally, the responsibility for interpreting radiographic images has been with medical physicians. X-rays should be used in tandem with other clinical information to confirm or deny a diagnosis and the role of ordering and interpreting $\mathrm{X}$-rays is now within the scope of the emergency nurse practitioners (NPs).

Methods: The purpose of this review was to examine the available evidence defining the ability of emergency NPs to appropriately order and interpret radiographs. A literature search was performed to identify papers on emergency NP X-ray accuracy and appropriateness compared to medical physicians.

Results: A total of 58 publications were identified, and of these 50 papers had no direct relevance to emergency NPs. The eight studies concluded that advanced specially trained nurses are able to order and interpret X-rays to a level comparable to that of their medical colleagues. However, there was a lack of homogeneity in the level of experience of practitioners examined. The physician level of experience reported was from junior doctors to registrar and consultant level and nurses were not always NPs but categorized by years of experience in ED. Methods described included rating scales, benchmarking against radiologists, specificity and sensitivity and auditing techniques. The numbers of $X$-rays used in each studied also varied greatly from 30 to 2000 radiographs and the majority of studies were performed in the United Kingdom. Overall with the nurses' interpretations, the rate of false negatives and false positives was low.

Conclusions: From the studies examined, it is difficult to extrapolate an acceptable level or standard for nurse practitioners from this research and clearly further research needs to be performed, especially in the local context.

(c) 2008 College of Emergency Nursing Australasia Ltd. Published by Elsevier Ltd. All rights reserved.
\end{abstract}

* Corresponding author. Tel.: +6139076 3933; fax: +61390763938.

E-mail address: g.lee@latrobe.edu.au (G. Lee).

1574-6267/\$ - see front matter ๔ 2008 College of Emergency Nursing Australasia Ltd. Published by Elsevier Ltd. All rights reserved. doi:10.1016/j.aenj.2008.11.004 


\section{Introduction}

The role of the emergency nurse practitioner (NP) is evolving within emergency healthcare provision. An important aspect of a role should, by necessity, be ongoing evaluation of both the new processes implemented by the role and the efficacy of these changes. Many studies from both the United Kingdom (UK) and United States of America (USA) have evaluated the role of the nurse practitioner in a variety of settings. Much of the data has focused on potentially superficial and subjective indicators of quality, such as waiting times and patient satisfaction, which impact on the patients' experience but not on key performance indicators such as missed fractures as a result of X-ray misinterpretation for example. Some research has already been carried out in the state of Victoria (Australia) on the outlined indicators such as waiting time, staff knowledge of the NP role and NP implementation ${ }^{1-4}$ and demonstrated positive results.

Emergency NPs have been practicing in emergency departments (EDs) in both the USA and UK for many years. The role arose in the USA in the 60 s out of increased demand for health care and shortfalls in medical staffing. ${ }^{5}$ In the state of Victoria, the NP role was introduced in 1998 as part of a demonstration project funded by The Department of Human Services. ${ }^{6}$ In 2004, eight emergency departments in metropolitan Melbourne were given funding to set up sustainable models of practice for emergency NPs. There are currently 17 endorsed NPs in ED in Victoria. ${ }^{7}$

The development of the emergency NP role has given experienced emergency nurses the scope to expand and extend their skills and knowledge including ordering and initiating diagnostic imaging and consequent radiological interpretation. ${ }^{1,7}$ The role of radiography within the context of emergency services provided by emergency NPs is to aid in the accurate diagnosis of trauma or illness for those presenting with limb pain with possible fractures. ${ }^{8,9}$ Traditionally, the responsibility for interpreting radiographic images has been with medically trained physicians. ${ }^{10}$ As X-ray ordering and interpretation are now part of the emergency NP role, a standard or level of accuracy in X-ray interpretation needs to be defined to ensure a comparable standard of patient care compared to current clinical practice (that is, medical physicians).

The purpose of this literature review, therefore, was to identify and describe the available evidence defining the ability of emergency NPs to appropriately order and interpret radiographs.

\section{Review method}

A literature search was performed to examine the nurse practitioner's role focusing on radiograph interpretation and accuracy of interpretation. Medline (OVID 1966-present), CINAHL and the Cochrane Database were queried using the search strategy: (Nurs\$ AND Practition\$) AND (radiograph\$ OR radiolog\$ OR X-ray) AND (order\$, request\$, interpret\$ OR result\$), limited to English language literature in humans.

\section{Findings}

The number of studies found was 58 with 50 having no relevance to emergency nurse practitioners. The remaining studies are summarized in Table 1 .

\section{Ordering X-rays}

The majority of studies focus on interpreting $X$-rays and only four papers specifically investigated the ordering of $X$ rays. ${ }^{11-14}$ All studies varied in which staff were involved and in their methods. In Sakr's study, ${ }^{12}$ all X-rays were reviewed by an ED physician with 1453 patients enrolled and 142 staff were assessed from inexperienced to experienced emergency NPs and senior house officers (SHOs), ${ }^{12}$ whereas in Derkson's study only sixteen nurses (with no emergency NPs) were involved in the study with eight senior house officers as the control group. ${ }^{11}$ Benger only examined four nurses in their study (not emergency NPs) comparing their results to two ED consultants. ${ }^{13}$ The primary aim of the study was to test telemedicine and determine if nurses could work alone in the unit. ${ }^{13}$ The ability of the emergency NP to appropriately order X-rays has found that adequately trained emergency NPs are able to accurately order (and interpret) limb X-rays to an equal standard of senior emergency doctors. ${ }^{11-13}$

As previously stated, the studies differed in their methodology with some studies having written protocols and inclusion criteria in ordering X-rays. One study demonstrated inclusion and exclusion criteria-only permitted suspected upper limb fractures less than $72 \mathrm{~h}$ to be included and suspected radio-opaque foreign body while children under 5 years and with multiple injuries were excluded. ${ }^{13}$ Derkson ${ }^{11}$ only examined 60 ankle and foot X-rays with 30 X-rays for the 16 nurses to review and 30 X-rays for the doctors to review with a total of 12 fractures in each group. ${ }^{11}$ The approach Sakr chose was descriptive, did not provide study criteria and the methodology did not allow statistical analysis. $^{12}$

Overall, the results were positive in favour of the emergency NPs when appropriateness of ordering X-rays was examined. Of the 300 X-rays requested by nurses, $3.7 \%$ of X-rays requested were deemed unnecessary or ordered inappropriately, ${ }^{13}$ compared to $13 \%$ in Sakr study. ${ }^{12}$ Barr audited 85 X-ray requests between NPs and SHOs and reported on the missed fractures and not on whether $X$ rays were deemed necessary. ${ }^{14}$ Only one study investigated whether there were any X-rays deemed necessary but were not ordered and this was $3.5 \% .^{12}$

From an educational perspective, the preparation of nurses to interpret $X$-rays is not discussed in two of the papers. ${ }^{12,13}$ With the 16 nurses in a peripheral unit, one pre and post-test educational session was performed and demonstrated significant improvements in ordering and interpretation. ${ }^{11}$ The authors stated that nurses only had basic nursing qualifications with no specialist training. Unfortunately, the study design did not allow for the correlation of physical findings and assessment into the appropriateness of X-ray ordering or findings. 
Table 1 Overview of studies.

\begin{tabular}{|c|c|c|c|c|}
\hline Study & Methods & Participants & Interventions & Outcomes \\
\hline Sakr (1999) & $\begin{array}{l}\text { Patients prospectively } \\
\text { enrolled. Primary outcome } \\
\text { was the adequacy of care } \\
\text { (history taking, patient } \\
\text { examination, interpretation } \\
\text { of radiographs, treatment } \\
\text { decision, advice and } \\
\text { follow-up) as determined by a } \\
\text { single reviewer (emergency } \\
\text { physician). }\end{array}$ & $\begin{array}{l}1453 \text { patients randomized to } \\
\text { care by NPs }(n=704) \text { or junior } \\
\text { doctors }(n=749) .\end{array}$ & $\begin{array}{l}\text { Rates of unnecessary and } \\
\text { un-requested X-rays (research } \\
\text { registrar's opinion was } \\
\text { arbiter). }\end{array}$ & $\begin{array}{l}\text { Requests for radiography } \\
\text { were different between } \\
\text { both groups and with } \\
\text { research registrar. } 13 \% \\
\text { of all radiographs } \\
\text { deemed unnecessary, } \\
\text { and in } 3.5 \% \text { they were } \\
\text { deemed necessary but } \\
\text { not ordered. No } \\
\text { between-group } \\
\text { difference in adequacy } \\
\text { of requests. Both groups } \\
\text { were similarly accurate } \\
\text { in their radiograph } \\
\text { interpretation. } \\
\text { Opinion based. Poor gold } \\
\text { standard. Descriptive } \\
\text { statistics, but good } \\
\text { sample size. }\end{array}$ \\
\hline Derksen (2006) & $\begin{array}{l}\text { Prospective study: } 60 \text { ankle } \\
\text { and foot radiographs ( } 30 \\
\text { each, } 12 \text { fractures in each } \\
\text { group). Pooled sensitivity and } \\
\text { specificity used. }\end{array}$ & $\begin{array}{l}16 \text { 'specialized' emergency } \\
\text { nurses tested before and } \\
\text { after an educational session. } \\
\text { Control group of } 8 \text { senior } \\
\text { house officers. }\end{array}$ & $\begin{array}{l}\text { Education consisted of a } \\
\text { 1-day course on ankle and } \\
\text { foot distortions by surgeon } \\
\text { and radiologist. }\end{array}$ & $\begin{array}{l}\text { Before education } \\
\text { session, specialized } \\
\text { emergency nurses had } \\
\text { sensitivity } 0.87 \text { vs. } 0.93 \\
\text { for the control group, } \\
\text { and specificity } 0.87 \text { vs. } \\
0.93(p<0.05) \text {. After } \\
\text { training, sensitivity and } \\
\text { specificity were } 0.89 \text { and } \\
0.92 \text {, respectively } \\
\text { (significantly improved). } \\
\text { Lack of clinical } \\
\text { correlation with X-rays, } \\
\text { so does not represent } \\
\text { real clinical practice. } \\
\text { Nursing group were not } \\
\text { NPs. } \\
\text { Extensive statistical } \\
\text { analysis but small } \\
\text { sample size. }\end{array}$ \\
\hline
\end{tabular}




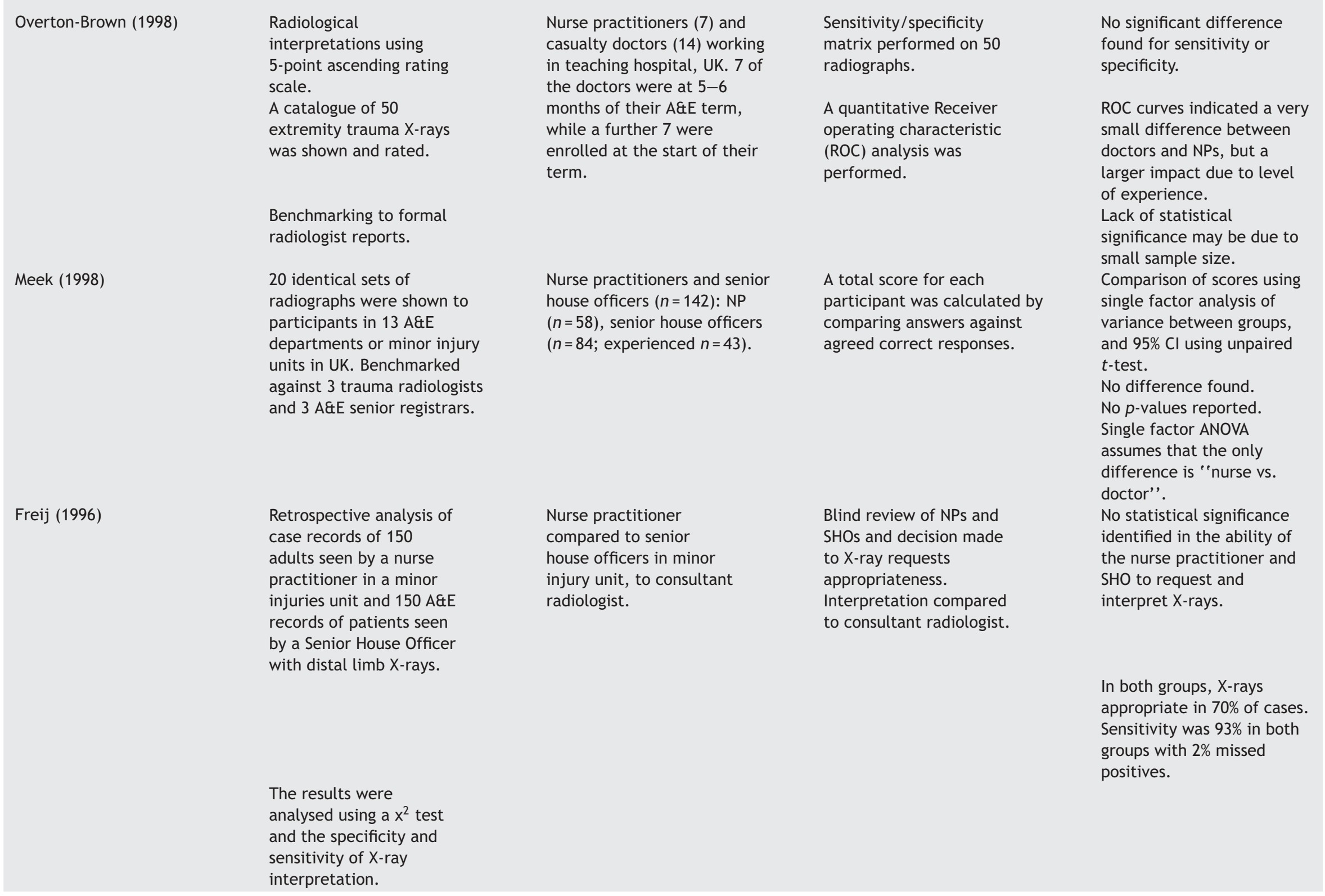




\begin{tabular}{|c|c|c|c|c|}
\hline Study & Methods & Participants & Interventions & Outcomes \\
\hline Summers (2005) & $\begin{array}{l}\text { Study participants were } \\
\text { shown } 30 \mathrm{X} \text {-rays and given a } \\
\text { brief patient history. }\end{array}$ & $\begin{array}{l}\text { The sample population was } \\
\text { drawn from a single A\&E } \\
\text { dept: } 20 \text { nurses with } 1-10 \\
\text { years experience and divided } \\
\text { into }>5 \text { years experience } \\
(n=10) \text { and those with }<5 \\
\text { years }(n=10) \text {. }\end{array}$ & $\begin{array}{l}\text { The nurses were given a score } \\
\text { of one point for the correct } \\
\text { identification of a fracture or } \\
\text { normal X-ray and half a point } \\
\text { for the ability to recognise an } \\
\text { X-ray as abnormal without } \\
\text { specifying the fracture. }\end{array}$ & $\begin{array}{l}\text { The group of nurses with }>5 \\
\text { years experience had a } \\
\text { mean of } 26.2 \text { (SD 1.36). } \\
\text { Junior group of nurses had } \\
\text { a mean score of } 22 \text { (SD } \\
\text { 3.3). }\end{array}$ \\
\hline Barr et al. (2000) & $\begin{array}{l}\text { Retrospective paper audit of } \\
85 \text { X-ray requests from SHOs } \\
\text { and Nurse Practitioners. }\end{array}$ & $\begin{array}{l}\text { Nurse Practitioners and } \\
\text { SHOs in Northern Ireland. }\end{array}$ & $\begin{array}{l}\text { X-ray requests examined by } \\
\text { consultant radiologist and } \\
\text { compared to SHO and NP } \\
\text { findings. }\end{array}$ & $\begin{array}{l}\text { Of the } 85 \text { requests from } \\
\text { NPs, } 15 \text { were found to have } \\
\text { fractures when interpreted } \\
\text { by radiologists. The NP } \\
\text { diagnosed } 17 \text { with one false } \\
\text { negative and three false } \\
\text { positives. } \\
\text { From SHOs: } 15 \text { fractures } \\
\text { were diagnosed, } 2 \text { false } \\
\text { negatives and } 2 \text { false } \\
\text { positives from } 85 \text { requests. }\end{array}$ \\
\hline Tachakra (2002) & $\begin{array}{l}\text { Retrospective study of } 2000 \\
\text { radiographs taken in a minor } \\
\text { injuries unit run by ENPs. }\end{array}$ & $\begin{array}{l}\text { Radiographers, NPs } \\
\text { Emergency consultants and } \\
\text { consultant radiologists were } \\
\text { sequentially responsible for } \\
\text { reporting on X-rays. }\end{array}$ & $\begin{array}{l}\text { X-rays were examined in } \\
\text { batches of } 500 \text {, with the } \\
\text { results of all disciplines } \\
\text { compared, with the gold } \\
\text { standard being that of the } \\
\text { consultant radiologist, or a } \\
\text { second radiologist where } \\
\text { there had been disagreement } \\
\text { between the groups. }\end{array}$ & $\begin{array}{l}\text { The summary statistics } \\
\text { showed ENP to have and } \\
\text { accuracy of } 97.75 \% \\
\text { compared to Consultant } \\
98.85 \% \text { and first Consultant } \\
\text { Radiologist } 98.7 \% \text {. } \\
\text { Small increase in accuracy } \\
\text { for NPs over time } \\
\text { demonstrated. }\end{array}$ \\
\hline Benger (2002) & $\begin{array}{l}\text { Prospective study of } 300 \\
\text { radiographs orders by NPs. }\end{array}$ & $\begin{array}{l}4 \text { nurse working in a } \\
\text { peripheral unit compared } \\
\text { with a gold standard derived } \\
\text { from the interpretations of } 2 \\
\text { emergency physicians. }\end{array}$ & $\begin{array}{l}\text { The first } 300 \text { X-rays requested } \\
\text { by the } 4 \text { nurses, of patients } \\
\text { presenting after limb trauma, } \\
\text { were assessed by } 2 \text { senior } \\
\text { doctors in emergency } \\
\text { medicine, one in person and } \\
\text { one via a telemedicine link. } \\
\text { The nurse asked to provide } \\
\text { provisional interpretation of } \\
\text { the X-ray and compared to } \\
\text { emergency physicians. }\end{array}$ & $\begin{array}{l}11 \text { X-rays were judged to } \\
\text { be inappropriately } \\
\text { ordered, } 10.7 \% \text { of nurse } \\
\text { interpretations disagreed } \\
\text { with emergency physicians. } \\
26 \text { false positives out of } 32 \\
\text { cases, } 4 \text { false negatives and } \\
2 \text { where an abnormality } \\
\text { was misidentified. } \\
\text { No inter-observer } \\
\text { difference in error rates. }\end{array}$ \\
\hline
\end{tabular}




\section{Interpreting X-rays}

The remaining studies examined the interpretation of X-rays (with differing levels of emergency nursing and physician experience). ${ }^{10,14-17}$ The results are presented in varying methods including the use of auditing and a rating scale. ${ }^{13,14}$ One study performed a retrospective audit comparing NPs and Senior House Officers (SHOs) with a consultant radiologist reviewing $85 \mathrm{X}$-ray requests and 15 fractures were reported amongst the sample. ${ }^{13}$ One false negative for NPs and two for SHOs, in a sample that only included 15 true positives each. The authors also commented on cases where NP and SHOs were unsure of interpretation but it was unclear how this data of "query fracture" ' was extracted in a retrospective study. Tachakra performed a comparative study where the ability peripheral limb X-rays accurately was examined. ${ }^{10}$ In a study of 2000 radiographs, the findings of the NPs were compared to radiographers (initial report), A\&E Consultants (reviewed all radiographs within $24 \mathrm{~h}$ ) and Consultant Radiologists (final report). This was done in batches of 500 radiographs with the unstated assumption that diagnostic accuracy will increase with familiarity, and demonstrated a non-significant improvement over time. A failing of this study was that the NPs were not blinded to the radiographer's initial report, however this represents the "real-world" practice in that particular unit. The authors showed a comparable level of accuracy in all groups. The authors commented on their inability to perform certain statistical test (specifically the receiver operating characteristic curves, ROC analysis or Kappa statistics) due to the study design. ${ }^{10}$

Overton-Brown and Anthony compared the X-ray interpretation skills of doctors and nurses with consultant radiologists using catalogues of 50 radiographs reviewed from real cases of extremity trauma. ${ }^{15}$ The results of the two groups (seven NPs and 14 doctors) were recorded using a $1-5$ ascending rating scale and through this process a positive or negative finding was determined, as well as the degree of certainty with which that response was made. The authors used the radiologist reports as the benchmark to assess interpretation skills. The receiver operating characteristic analysis reported no statistical differences between the two groups. The receiver operating characteristic is a rigorous statistical method and therefore probably provides more accurate results than other studies where opinions on interpretation were used for example. ${ }^{16}$

In a review by Hardy and Barrett, the authors focused on the difficulty in interpreting trauma X-rays and also on comparing practitioners and commented on the difficulty of establishing an appropriate level of accuracy. ${ }^{16}$ Their findings found a marked variation in the ability of senior house officers to interpret trauma X-rays. Valid concerns are raised about comparing emergency NPs abilities to the varying standard of their medical colleagues, concluding that a similar ability does not imply a satisfactory level of competence. They did however correlate the length of emergency experience by the practitioner (both medical and nursing) with a greater accuracy of radiograph interpretation. The length of experience is highlighted by Meek et al. in distal limb radiographs. ${ }^{17}$ Their research demonstrated that NPs were able to interpret the films to a standard equal to SHOs with three to five months' experience in 13 minor injury units. The authors used the gold standard of three trauma radiologists and total scores were calculated for each participant in the study. A critical comment on this study was that no $p$-values were reported and only an analysis of variance statistical test (ANOVA) was used. The clinical experience of the nurse is also highlighted in another study where the researchers divided nurses into two groups (one group with less than 5 years ED experience and the second with more than 5 years experience) and in the more experienced group, $\mathrm{X}$-ray interpretation was better. ${ }^{18}$

Few studies have examined both ordering and interpreting X-rays. In one study, four nurses were working to written protocols developed following consultation with senior staff in radiology and emergency medicine and were found to be able to appropriately request and interpret $\mathrm{X}$-rays to a high standard. ${ }^{13}$ Study participants were given formal education and training prior to the commencement of the study. ${ }^{12}$ The nurses X-ray interpretation was found to have a sensitivity of $96 \%$ and specificity of $87 \%$ (comparable to other studies). ${ }^{10,18}$ In another study, researchers retrospectively compared 150 case logs from NPs and SHOs in one ED in the UK where a consultant radiologist, an emergency consultant and a nurse practitioner reviewed case logs from patients presenting with injuries distal to the elbow or knee. ${ }^{19}$ The findings revealed that the difference in emergency NPs ability to request and interpret radiographs compared with medical staff was not statistically significant, concluding that appropriately trained NPs are at least as good as medical staff. Of note, was that the sensitivity of interpretation was above $90 \%$ in both groups with only $2 \%$ missed positive results. ${ }^{19}$

\section{Discussion}

The studies concluded that advanced specially trained nurses are able to accurately order and interpret X-rays to a level comparable to that of their medical colleagues. However, there was a lack of homogeneity in the level of experience of practitioners examined. Methods described included rating scales, benchmarking against radiologists, specificity and sensitivity and auditing techniques. The numbers of X-rays used in each studied also varied greatly from 30 to 2000 radiographs and the majority were performed in the UK. The physician level of experience reported was from junior doctors to registrar and consultant level and nurses were not always NPs but categorized by years of experience in ED. Overall with the nurses' interpretations, the rate of false negatives and false positives was low and small numbers of missed abnormalities were reported. It also becomes apparent that nurses' $X$-ray interpretation is more frequently audited and assessed than their medical colleagues.

All studies indicated that NPs have no formal training in X-ray interpretation and no universal approach has been identified with much variation in the educational methods reported. One study reviewed practices of X-ray ordering in triage in the UK but did not specifically examine NP practices. ${ }^{20}$ The lack of uniformity in formal X-ray review was evident in one review of 198 hospitals. ${ }^{16}$

Although some studies have reported nurses observed abnormalities when none were present resulting in a number of false positive results, most authors state that this 
is safer than false negatives. ${ }^{13,21}$ High rates of sensitivity and specificity were observed amongst emergency nurses. A certain percentage of $\mathrm{X}$-rays were unnecessary but the rate varies from $3.7 \%$ to $13 \%{ }^{12,13}$ Inconsistent and unacceptable ability of senior house officers to interpret X-rays has been reported by Hardy and Barrett and this highlights the variability of interpretation skills amongst one level of practitioners when interpreting the data. ${ }^{16}$ What becomes apparent is that there are varying levels of doctors and nurses included in these studies. ${ }^{13}$ As a result of having different control groups, it is difficult to extrapolate from this research a minimum expected level or standard for NPs. To achieve this, one would have to create a series of studies with identical methodology and different control groups for benchmarking purposes.

The acknowledged medical experts in interpretation of radiographic images are radiologists and their opinion is generally been regarded as the gold standard measure of competency. The biggest obstacle to assessing X-ray interpretation accuracy is the lack of a gold standard with studies using different health professionals to define the "gold standard". From consensus, the benchmark is set by the consultant radiologist but no single tool is available to score $X$-ray accuracy with many different methods of analysis presented in the papers.

One question that this topic raises is what standard should NPs aim for NP ANMC competencies have been developed in Australia but only encompass competencies and do not extend to specific scopes of practice. ${ }^{22}$ Another issue is what constitutes adequate $\mathrm{X}$-ray interpretation education that deems a person competent? A systematic approach to X-ray interpretation is recommended but to date no internationally recognised approach is available. Further multi-disciplinary research is needed involving NPs, radiologists and physicians (ED, orthopaedic and trauma).

A criticism of the studies is that only one of the studies identified adverse outcomes such as missed fractures. One weakness found in the majority of the studies was the lack of reporting of ED representations and complications. The majority of reviewed studies were UK based and single-centre. One issue would be the differences in educational training between nurses and medical staff in UK and other countries and even within the UK, no uniformity exists. However this should not prevent further research and debate amongst the relevant health professionals. The one systematic review on NPs was in the primary care setting but showed that nurses can provide equivalent care of doctors. ${ }^{23}$

Limitations of this review are that it only included English language publications and due to time constraints we only performed a brief literature review and not a systematic review. Also, it is really unclear about the education that health professionals undergo in order to be able to interpret $\mathrm{X}$-rays and this will probably become a more contentious area as nurse initiated X-rays are implemented in many EDs.

\section{Conclusion}

Radiographic ordering and interpretation is an important aspect of the extended scope of the nurse practitioner in the ED. The majority of the studies examining ordering and interpreting $\mathrm{X}$-rays is from the UK and compares emergency
NPs and advanced emergency nurses to different levels of physicians. No gold standard tool is currently in use and this remains a problem with each study undertaking different study designs. The results demonstrate that nurses have good sensitivity and specificity and high levels of accuracy in X-ray interpretation and are comparable to their ED physician colleagues. Although, there is good support for emergency nurses interpreting X-rays, further research in the Australasian area needs to be undertaken to examine if practices are similar here.

\section{Conflict of Interest/Funding Declarations}

None declared.

\section{References}

1. Jennings N, O'Reilly G, Lee G, Cameron P, Free B. Implementing the Emergency Nurse Practitioner into a major inner city trauma centre. A new model of care delivery for patients in the ED setting. J Clin Nurs 2008;17:1044-50.

2. Lee $G$, Jennings N, Bailey M. An exploration of staff knowledge on Nurse practitioner's role in the emergency department. Accid Emerg Nurs 2007;15(2):79-87.

3. Lee $G$, Jennings $N$. A comparative study on characteristics of did not wait patients versus those that were seen by the nurse practitioner. Austral Emerg Nurs J 2006;9:179-85.

4. Martin R, Considine J. Knowledge and attitude of ED staff before and after implementation of the emergency Nurse Practitioner role. Austral Emerg Nurs J 2005;8:73-8.

5. Asubonteng P, McCleary KJ, Munchus G. Nurse practitioners in the USA-their past, present and future: some implications for the health care management delivery system. Health Manpower Manag 1995;21:3-10.

6. Department of Human Services. Nurse Practitioner Project. Available from <http://www.health.vic.gov.au/nursing/ furthering/practitioner.htm> [accessed 15.07.08].

7. Nurses Board of Victoria website, Nurse Practitioner Endorsement. Available from <http://www.nbv.org.au/ registration/nurse-practitioner.aspx\#process> [accessed 15.07.08].

8. Allerston J, Justham D. Nurse practitioners and the Ottawa Ankle Rules: comparisons with medical staff in requesting X-rays for ankle injured patients. Accid Emerg Nurs 2000;8:110-5.

9. Hardy $M$, Barrett $C$. Interpreting trauma radiographs. $J$ Adv Nurs 2003;44(1):81-7.

10. Tachakra S, Mukherjee P, Smith C, Dutton D. Are accident and emergency consultants as accurate as consultant radiologists in interpreting plain skeletal radiographs taken at a minor injury unit? Eur J Emerg Med 2002;9(2):131-4.

11. Derksen RJ, Bakker FC, Heilbron EA, vGeervliet PC, Spaans IM, de Lange-de Klerk ESM, et al. Diagnostic accuracy of lower extremity X-ray interpretation by 'specialized' emergency nurses. Eur J Emerg Med 2006;13:3-8.

12. Sakr M, Angus J, Perrin J, Nixon C, Nicholl J, Wardrope J. Care of minor injuries by emergency nurse practitioners or junior doctors: a randomised controlled trial. The Lancet 1999;354(9187):1321-6.

13. Benger JR. Can nurses working in remote units accurately request and interpret radiographs? Emerg Med $J$ 2002;19:68-70.

14. Barr M, Johnston D, McConnell D. Patient satisfaction with a new nurse practitioner service. Accid Emerg Nurs 2000;8:144-7. 
15. Overton-Brown P, Anthony D. Towards a partnership in care: nurses' interpretation of extremity trauma radiology. $J$ Adv Nurs 1998;27(5.):890-6.

16. Hardy $M$, Barrett $C$. Interpretation of trauma radiographs by radiographers and nurses in the UK: a comparative study. $\mathrm{Br} \mathrm{J}$ Radiol 2004;77:657-61.

17. Meek S, Kendall J, Porter J, Freij R. Can accident and emergency nurse practitioners interpret radiographs? A multicentre study. J Accid Emerg Med 1998;15:105-7.

18. Summers A. Can nurses interpret X-rays safely without formal tuition? Accid Emerg Nurs 2005;13(3):162-6.

19. Freij RM, Duffy T, Hackett D, Cunningham D, Fothergill J. Radiographic interpretation by practitioners in a minor injuries unit. J Accid Emerg Med 1996;13:41-3.
20. Lindley-Jones M, Finlayson BJ. Triage nurse requested X-rays-are they worthwhile? J Accid Emerg Med 2000;17:103-7.

21. Maebrook AF, Dale B. Can nurse practitioners offer a quality service? An evaluation of a year's work of a nurse led minor injury unit. J Accid Emerg Med 1998;15:266-8.

22. Australian Nursing and Midwifery Council. National Competency Standards for the Nurse Practitioner. Available from: <http://www.anmc.org.au/docs/Competency_Standards_for_ the_Nurse_Practitioner.pdf>; 2006 [accessed 15.12.2007].

23. Horrocks S, Anderson E, Salisbury C. Systematic review of whether nurse practitioners working in primary care can provide equivalent care to doctors. BMJ 2002;324: 819-23. 